\title{
Notícias da REM
}

\section{A guerra do aço ainda vai durar*}

A guerra do aço continua, apesar da vitória obtida pelo Brasil, pela União Européia e por mais seis países contra as barreiras impostas pelos Estados Unidos a vários tipos de produtos siderúrgicos. A Organização Mundial do Comércio (OMC) anunciou na sexta-feira da semana passada que as salvaguardas adotadas no começo de 2002 pelo governo americano foram consideradas ilegais, isto é, contrárias às normas internacionais. O governo americano manifestou a intenção de recorrer - o que lhe permitirá, até a decisão final, manter a imposição de sobretaxas de até $30 \%$.

No mesmo dia, as autoridades americanas anunciaram a adoção, em caráter preliminar, de tarifas antidumping para a importação de cabos de aço provenientes do Brasil (119\%), da Índia (103\%), do México (77\%), da Coréia do Sul (54\%) e da Tailândia (12\%).O governo de Washington continua, portanto, disposto a atender ao lobby da superada indústria siderúrgica dos Estados Unidos, garantindo-lhe, a qualquer custo, proteção contra a concorrência de fabricantes mais modernos e mais competitivos. As ambições eleitorais do presidente George W. Bush, prejudicadas pelo aumento do desemprego nos Estados Unidos, devem permanecer como um importante fator de orientação de sua política de comércio internacional.

É pouco provável, a julgar pelos argumentos que fundamentaram a decisão da OMC, que os Estados Unidos tenham sucesso em seu recurso contra a condenação. De acordo com a sentença, nem as importações haviam crescido como os americanos alegaram, nem ocorreu, no fluxo de comércio de aço, uma alteração repentina e inesperada. Além disso, os americanos foram incapazes de mostrar, na maioria dos casos, uma relação causal entre as importações e as dificuldades enfrentadas por sua indústria. Não houve como negar que os problemas da siderurgia americana são decorrentes, mesmo, de seu enfraquecimento diante de concorrentes que investiram e se modernizaram.

O recurso, no entanto, servirá para prolongar a indevida proteção à indústria dos Estados Unidos, ainda que o País fique sujeito a retaliações comerciais para compensação das perdas impostas aos parceiros.

As novas medidas, anunciadas na sexta-feira, são mais uma demonstração de como é perigoso, para o comércio mundial, o uso arbitrário de instrumentos antidumping. As normas em vigor deixam aos países grande poder de arbítrio no uso dessas armas. Essa é a razão pela qual o Brasil e outros países defendem a adoção de regras mais estritas para as políticas antidumping. O Brasil tem defendido a modificação das normas tanto na discussão da Área de Livre Comércio das Américas (Alca) quanto nas negociações da Rodada de Doha, no âmbito da OMC. Lobbies do setor privado americano, com apoio de congressistas, são contrários à criação de regras mais estritas, que reduzam o poder de arbítrio do governo dos Estados Unidos. Esse tema será novamente dis- cutido, com certeza, no primeiro balanço geral da Rodada de Doha, na reunião ministerial marcada para setembro,em Cancun.

Os americanos têm procurado, além de utilizar os meios de proteção já disponíveis, conseguir dos principais fabricantes de aço um compromisso de redução da oferta. O assunto está em debate na Organização para a Cooperação e o Desenvolvimento Econômico (OCDE).

O Brasil tem interesse em que a oferta seja reduzida pelo meio mais eficiente e mais justo, ou seja, a eliminação das indústrias que sobrevivem apenas graças à proteção e a pesados subsídios. Não tem sentido, segundo o governo brasileiro, lançar o custo da redução da oferta sobre os produtores mais competitivos. Mas o Brasil também não pode aceitar um acordo que envolva restrições à sua política de financiamento, realizada exclusivamente, ou quase, por meio do Banco Nacional do Desenvolvimento Econômico e Social (BNDES). Qualquer acordo desse tipo apenas beneficiaria os países que já dispõem de canais diversos de financiamento barato. É pouco provável que se alcance em pouco tempo, nesse foro da OCDE, um acordo satisfatório para todos. Também nesse front, portanto, parece difícil a superação dos conflitos em torno do comércio internacional do aço.

\footnotetext{
*Publicado no jornal "O Estado de São Paulo" de 20/07/2003 na coluna "Notas e Informações".
}

\section{www.geologo.com.br}

O portal do Geólogo é um site independente não subordinados, política ou financeiramente a nenhuma associação, órgão, grupo ou empresa. Trata-se de um novo site (www.geologo.com.br), que tem por objetivo a renovação e a modernização da Geologia e da Mineração do Brasil.

Trata-se de um grupo de profissionais que contribuem para a elaboração do Geologo.com.br, com grande experiência e relevância nas várias áreas da geologia contemporânea do Brasil. Colabore! 


\section{Brasil será representado na Argentina pelo presidente da Samarco}

O presidente da Samarco, José Luciano Duarte Penido, foi o único executivo brasileiro a participar da $1{ }^{\text {a }}$ Conferência Argentina de Responsabilidade Social Empresária, que aconteceu em Tucumán, nos dias 7, 8 e 9 de julho. Ele foi convidado especial da Fundación Del Tucumán para apresentar um testemunho de responsabilidade social empresarial não apenas diante de centenas de empresários, acadêmicos, representantes de ONG's, como também do Presidente da República da Argentina, Nestor Kirchner.

Penido, além da Samarco, representou também o presidente do Instituto Ethos, Oded Grajew, atualmente assessor especial do presidente Lula, e a Federação das Indústrias do Estado de Minas Gerais (FIEMG), entidade da qual é vice-presidente e ainda presidente do Instituto de Cidadania e Voluntariado Empresarial. "O convite foi uma honra porque demonstrou o reconhecimento do compromisso e responsabilidade social que tem o Brasil, Minas Gerais e a Samarco", comentou.

Segundo Penido, a intenção foi apresentar aos argentinos o princípio de gestão empresarial através do qual as empresas devem assumir total responsabilidade por suas ações nas dimensões econômica, social e ambiental e oferecer exemplos práticos que ilustram esse conceito.

Entre outros objetivos, a Conferência visou a criar um espaço de trabalho e integração do empresariado da Argentina, coordenar ações e esforços e aplicar a responsabilidade social nas empresas como um novo modelo de gestão. Para isso, pretende difundir as melhores práticas do empresariado argentino que possam ser replicadas.

\section{Petrobras: descoberta no Golfo do México}

Petrobras anuncia descoberta no setor americano do golfo do México

A Petrobras e seus sócios - BHP Billiton, Total e Amerada Hess - anunciaram hoje descoberta de petróleo em águas ultraprofundas, no setor americano do Golfo do México, com a perfuração do poço exploratório $\mathrm{n}^{\circ} 3$, no prospecto de Chinook.

O resultado exploratório da descoberta de Chinook é encorajador e passará por avaliações exploratórias adicionais e estudos de desenvolvimentos da produção, para permitir uma melhor definição quanto ao tamanho da reserva.

A perfuração no poço Chinook $\mathrm{n}^{\circ} 3$, no bloco Walker Ridge 469, foi iniciada em 13 de janeiro de 2003, com o navio sonda C.R. Luigs posicionado em águas de 2.691 metros, tendo alcançado a profundidade final de, aproximadamente, 8.427 metros, encontrando uma coluna de petróleo de 189 metros, com 79 metros de espessura
Usiminas Mecânica transporta equipamento gigante

Guindaste fabricado em Ipatinga é a peça com maior comprimento já transportada no Brasil

A Usiminas Mecânica, fabricante de bens de capital (equipamentos e estruturas metálicas), controlada pela Usiminas, iniciou o transporte da lança de um guindaste com de 68 toneladas, 50 metros de comprimento, 3,5 metros de largura e 2,4 metros de altura. As partes do guindaste, fabricado pela Usiminas Mecânica na unidade industrial de Ipatinga, serão levadas até o porto de Praia Mole, no Espírito Santo. A lança é a peça com maior comprimento já transportada entre estados em território brasileiro.

O transporte será realizado pela empresa Transpesa Della Volpe que, sob a supervisão da Usiminas Mecânica, desenvolveu todo o estudo de viabilidade da tarefa. Serão utilizados um cavalo mecânico com tração dupla, marca Scania, com potência de 450 HP, e semireboque de conjunto modular hidráulico composto de dois dollyes, tendo quatro linhas de eixos com oito pneus por eixo cada um.

O transporte será realizado somente em dias úteis, do amanhecer ao por do sol, e com velocidade máxima de $30 \mathrm{~km} / \mathrm{h}$. O prazo de entrega está estimado entre seis e oito dias. Havéra escolta da Polícia Rodoviária Federal (PRF).

Chinook está localizado a aproximadamente $32 \mathrm{~km}$ ao sul da recente descoberta de Cascade, operado também pela BHP Billiton, no qual a PETROBRAS detém $25 \%$ de participação no poço descoberto, perfurado em 2002.

A participação da PETROBRAS nessas duas descobertas está em conformidade com o seu Plano Estratégico, representando importantes etapas na consolidação de um portfolio de exploração e produção de alta qualidade em águas profundas no Golfo de México.
1936 - 2003

Não esconda

seu trabalho.

Publique-o na REM.

67 anos

divulgando ciência. 


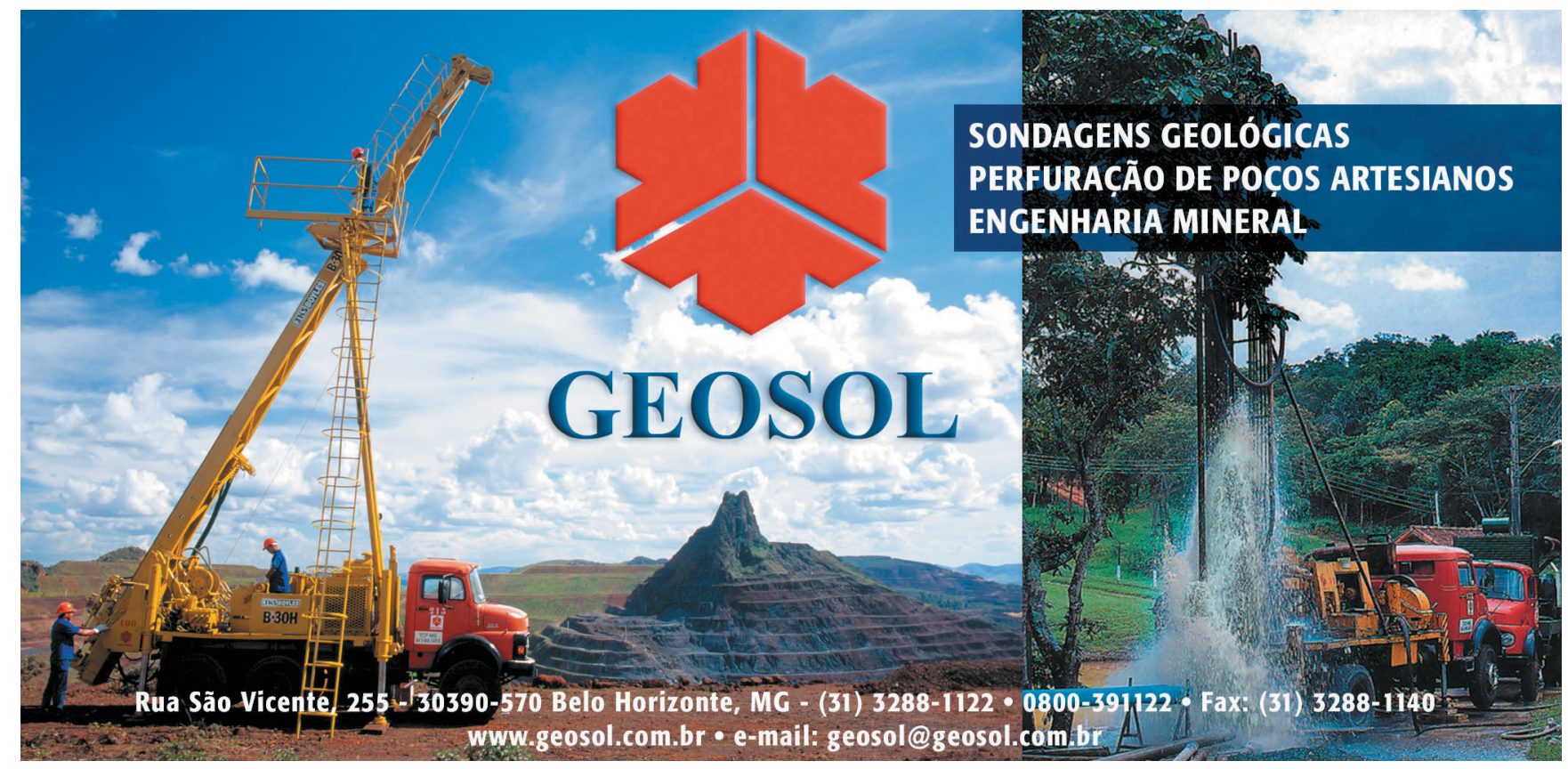

\section{Expansão das malhas de gasodutos}

Petrobras assina contratos para expansão das malhas de gasodutos sudeste e nordeste

A Petrobras assinou, em Nova Iorque, contratos para viabilizar o financiamento no valor de US\$ 1 bilhão para implantação do Projeto Malhas - expansão das malhas de gasodutos das Regiões Sudeste e Nordeste -, que ampliará a capacidade de transporte de gás natural no Nordeste, em 9 milhões de metros cúbicos/dia, nos próximos dois anos, podendo chegar a 14 milhões em 2012. Na Região Sudeste, a capacidade de transporte será ampliada em 13 milhões de metros cúbicos/dia, nos próximos dois anos.

Inicialmente o Projeto Malhas foi elaborado para atender à demanda das usinas incluídas no Programa Prioritário de Usinas Termelétricas - PPT. Hoje, entretanto, tem como principal objetivo garantir o suprimento da demanda do setor industrial, além de estimular a massificação do uso do gás natural, com o aproveitamento do combustível em projetos de co-geração e geração distribuída, para processos de aquecimento e refrigeração, nos segmentos residencial e comercial.

Com esse projeto, a Petrobras também pretende incrementar o consumo de gás natural no segmento automotivo, através da inserção do combustível nas frotas de transporte coletivo urbano, em substituição ao óleo diesel, visando à melhoria da qualidade do meio ambiente, nos grandes centros urbanos.
A ampliação da rede de gasodutos Sudeste e Nordeste é o primeiro de uma série de projetos que prevê a inserção mais intensa do gás natural na matriz energética brasileira. A ampliação da oferta do combustível estimulará, também, a sua utilização como matéria-prima para a indústria petroquímica.

\section{Projeto Malhas}

Com financiamento de cerca de $40 \%$ do Japan Bank for International Cooperation - JBIC (US\$ 394 milhões), o Projeto Malhas contará, ainda, com R\$830 milhões (aproximadamente US\$ 256 milhões) do BNDES, além de US\$ 250 milhões de um pool de bancos internacionais com garantia fornecida pela Nippon Export and Investiment Insurance - NEXI - e de uma parcela de capital próprio de tradings japonesas.

Para viabilizar o projeto, foram constituídas duas empresas de propósito específico, a Nova Transportadora do Nordeste S.A. (NTN) e a Nova Transportadora do Sudeste S.A - (NTS), cujo controle acionário é da Mitsui \& Co (40\%), Itochu Corporation e Mitsubishi Corporation (30\% cada uma).

A NTN e a NTS serão responsáveis pela captação dos recursos financeiros e pelos investimentos necessários à construção dos gasodutos e demais instalações e a Petrobras arcará com a compra da capacidade de transporte. Estima-se que com a implantação do projeto sejam gerados mais de 10 mil empregos diretos, durante a construção dos gasodutos, sendo superior a $70 \%$ o conteúdo nacional do empreendimento.

Os investimentos na ampliação da Malha Sudeste concentram-se na construção do Gasoduto Campinas - Japeri (RJ), com $442 \mathrm{~km}$ de extensão, que terá capacidade para transportar 8,7 milhões de metros cúbicos/dia de gás natural. $\mathrm{O}$ início da construção desse gasoduto está previsto para o segundo semestre de 2003, após a liberação do licenciamento ambiental pelo Ibama, e as obras devem estar concluídas em janeiro de 2005. O projeto prevê ainda a ampliação do sistema de compressão de gás da bacia de Campos.

A ampliação da Malha Nordeste prevê a implantação de sete gasodutos e ramais, com 962 km de extensão, a construção de oito citygates e a instalação de duas estações de compressão na Bahia, nos municípios de Candeias e Catu. Esse projeto vai possibilitar o atendimento à demanda de gás de natural já contratada naquela região. As obras de ampliação da Malha Nordeste deverão ter início também no segundo semestre, com término previsto para meados de 2005. 


\section{Geólogo lança livro}

O Geólogo Aramis Pereira Gomes (há 30 anos na CPRM - Serviço Geológico do Brasil, ex-Presidente da CRM - Cia Riograndense de Mineração - a maior produtora de carvão do país) lança o livro CARVÃO DO BRASIL / TURFA AGRÍCOLA, livro inédito no Brasil sobre nossa maior riqueza em energia ( cinco vezes mais que as reservas de petróleo ), tratando, em linguagem simples e didática, própria para público leigo, estudantes, professores, políticos, cientistas, etc. São feitos comparativos com as matrizes energéticas de vários países, e é feita uma orientação de como ter acesso em tempo real aos dados do World Energy Council (geo-cientistas). Também são relatadas curiosidades sobre carvão

\section{Áreas degradadas}

O $1^{\circ}$ EBT- Encontro Brasileiro de Tecnógeno deverá ser realizado em maio de 2004, na cidade de Ouro Preto.O evento foi aprovado pela ABGE, ABEQUA e UFOP, que serão os patrocinadores. $\mathrm{O}$ apoio de outras entidades é importante. Os interessados em ajudar, participar ou dar sugestões podem entrar em contato para maiores esclarecimentos.

Informações: Adriana

ebt2004ouropreto@yahoo.com.br e turfa no RS e SC, as térmicas a carvão, são apresentados os projetos em construção, as causas do sabor e aroma do whisky (defumação com turfa), sugestões para maior utilização do carvão nacional: energia em moeda nacional, fatores de multiplicações econômicas no "hinterland", trabalho e paz no campo (novos municípios). Também são comentados exemplos a serem seguidos pelo Brasil, como, por exemplo, a produção de energia a partir do carvão mineral em sistema pulverizado (mais barato) com grandes cuidados ambientais (nada a ver com o passado em SC), trabalho feito pela Austrália (carvão de mesma origem: continente de Gondwana e idade -280 milhões de anos).

Preço: R\$20,00 - Fone: 51 3334-2279

\section{CURSO: MBA em mármores e granitos}

Direcionado para profissionais de formação superior, técnicos e empresários, o curso está sendo organizado pela UFRJ e CETEM, além do CETEMAG e RETEQROCHAS, com o objetivo de formar e difundir conhecimentos e fundamentos do setor de rochas ornamentais, abrangendo a análise da cadeia produtiva e suas características operacionais. A iniciativa está alinhada à política de desenvolvimento do setor mineral realizada pelo Governo do Estado, destacando-se que o Rio já é o terceiro exportador nacional de rochas ornamentais em geral e o segundo em chapas polidas de mármores e granitos, gerando em torno de 17 mil empregos diretos em toda a cadeia produtiva. O MBA acontecerá simultaneamente em Cachoeiro do Itapemirim e informações podem ser obtidas em www.cetem.gov.br ou pelo end. eletrônico:adriano@cetem.gov.br.

\section{Curso de legislação mineral em São Paulo}

O Instituto Brasileiro de Direito Minerário (IBDM), com apoio de William Freire \& Advogados Associados, realiza nos dias 23 e 24 de outubro o Curso de Legislação Mineral, no Hotel Gran Mercure, em São Paulo. O curso, dirigido a advogados, geólogos, engenheiros de minas, funcionários e parceiros de empresas de mineração, tem programa básico de 14horas/aula. Inscrições até 30 de setembro.

Mais informações: 31 3261-9722

direitominerario@williamfreire.com.br.

\section{Rio tem plano de ação para o setor produtivo de brita}

Foi lançado, na FIRJAN, o Plano de Ação para o setor de brita e agregados, que tem por objetivo o desenvolvimento sustentável do setor produtivo e o atendimento da demanda para a construção civil e obras públicas nos dezessete municípios da Região Metropolitana do Rio de Janeiro, que é o segundo consumidor brasileiro, com 4,8 milhões de $\mathrm{m}^{3}$ de brita em 2002. Enquanto nos países industrializados o consumo per capita de brita e areia é de 8 t/hab/ano, no Brasil esse índice não passa de 2,3 t/hab/ano, demonstrando a carência de investimentos na melhoria da qualidade de vida da população. A cadeia produtiva da indús- tria de brita na Região Metropolitana, que inclui também os segmentos de areia, concreto e artefatos de cimento, congrega cerca de 40 mil postos de trabalho, dos quais em torno de 1.200 no segmento produtor de brita. A perspectiva de investimentos pesados em infra-estrutura e habitação nos próximos anos, que resultarão em significativo incremento da produção de brita, areia, tijolos e concreto, além dos demais materiais de construção, requer ações institucionais de grande eficácia estruturadas em um Plano de Ação fundamentado em estratégias harmonicamente integradas. O Estudo que serve de base ao Plano foi elaborado pelo Departamento de Geologia da
UFRJ e uma equipe de consultores associados à ConDet, com recursos do FNDCT/CTMIn e apoio do Governo do Estado e entidades empresariais, incluindo a FIRJAN e SINDIBRITA. O plano prevê diversas ações, destacandose a criação de um Fórum permanente de debates, reunindo governo e empresariado, que se encarregará de acompanhar as medidas a serem adotadas tanto do lado público como privado, incluindo aquelas relacionadas ao meio ambiente e ao processo de ocupação do espaço urbano.

Notícia veiculada no boletim informativo do DRM de 09/07/03. 
Mais uma vez a Minasligas mostra a seu compromissa cam a qualidade.
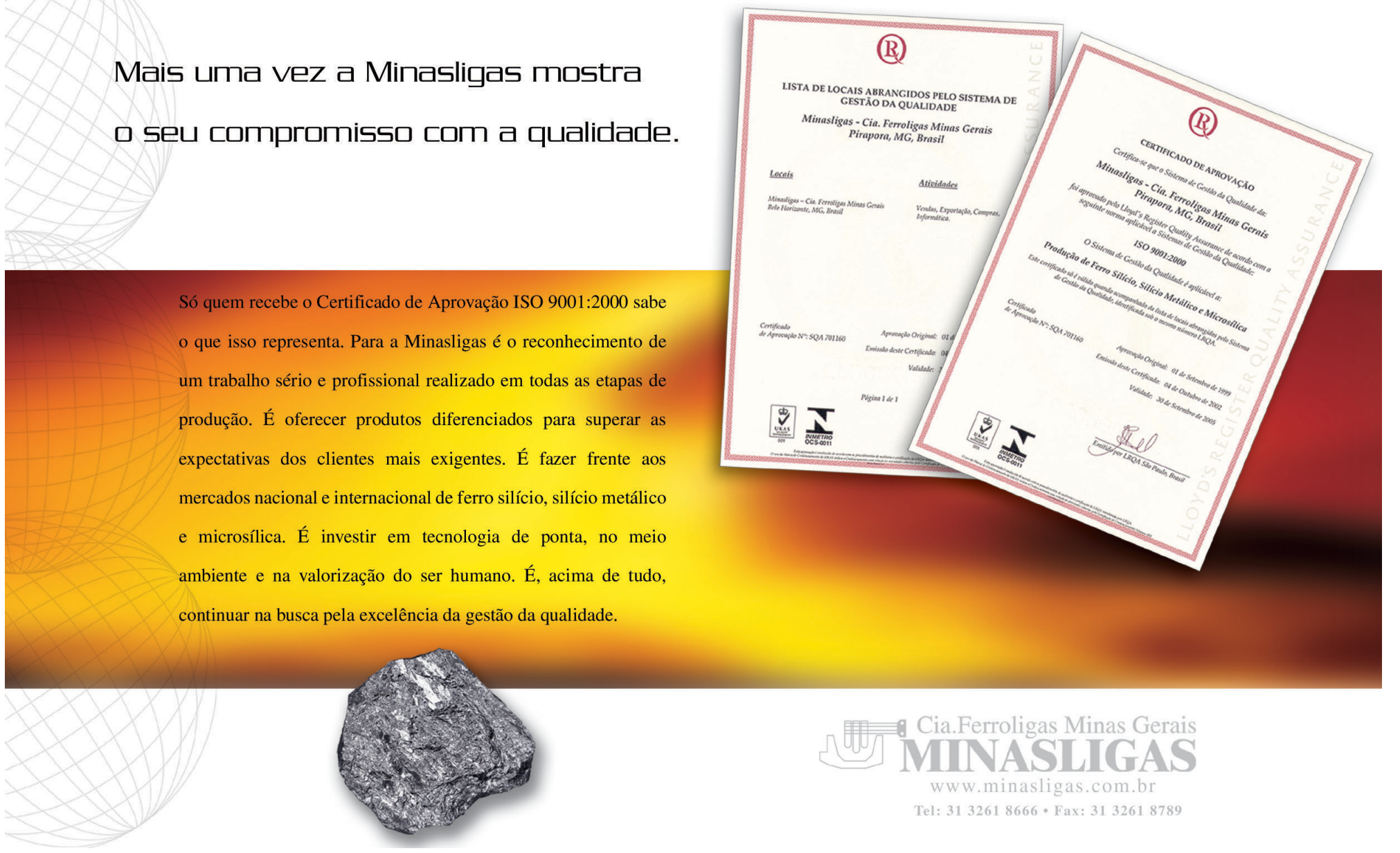

\section{Simpósio de Geologia de Minas Gerais}

\section{Semana de Estudos Geológicos - SICEG}

Temas Centrais: Geologia Regional e Ambiental

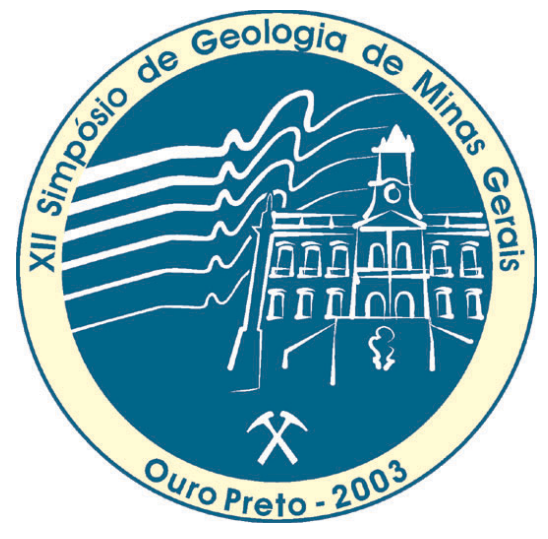

4 a 8 de novembro de 2003

Ouro Preto - UFOP

Informações e Inscrições:

ÉTICA Promoção de Eventos Ltda.

Rua Nossa Senhora do Brasil, 765

31130-090 - Belo Horizonte - MG

Fone: (31) 3444-4794 - Fax: (31) 3444-4329

E-mail: etica@net.em.com.br 


\section{Suprimentos de Base: Condição Estratégica para o Crescimento* \\ Rinaldo Campos Soares \\ Presidente da Usiminas \\ R\$ 36,8 milhões em projetos sociais e de meio ambiente}

O Brasil está atravessando um período de reformas e de conscientização centrado no megaobjetivo de reverter o longo período de estagnação da economia, que já dura vinte anos. Há algumas semanas, o Ministério do Planejamento emitiu um termo de referência, para discussão com o Conselho de Desenvolvimento Econômico e Social, onde, além de sinalizar que as políticas de crescimento, de inclusão social e de superação da vulnerabilidade externa passam necessariamente pela elevação dos investimentos em capacidade produtiva, evidenciou três aspectos, que acreditamos fundamentais para a construção de um projeto nacional de desenvolvimento do país: a taxa de ocupação da capacidade de produção, a competitividade global e o coeficiente de insumos importados.

Não há dúvida de que o Brasil conta com um conjunto de fatores favoráveis à expansão econômica, como o potencial da economia, as demandas reprimidas, tanto em infra-estrutura, quanto no suprimento de bens de capital e de consumo; a atratividade mundial do país e as macroalianças continentais.

Mas estamos travados por um conjunto de fatores desfavoráveis, como a incapacidade de investimento do governo, sufocada pelo serviço da dívida pública; a vulnerabilidade externa; e as políticas monetárias e de crédito, que retiram da economia recursos que poderiam estar sendo canalizados para o investimento e o consumo, a taxas de juros próximas das que se praticam nos demais países emergentes.

Com um desempenho comparativo, considerando os últimos 20 anos, nem é justo classificarmos o Brasil como país emergente, que têm essa denominação por crescerem mais que a média mundial. A continuar crescendo a um ritmo inferior a média mundial, o Brasil poderá caracterizar-se como submergente.

Evitar esse desastre é o maior desafio da nação atualmente. E é aí que entram os três aspectos que citamos no início. Dois deles são essenciais para remover a vulnerabilidade externa: a sustentação de cadeias produtivas globalmente competitivas e a redução dos coeficientes de importação de cadeias fortemente dependentes de suprimentos externos.

Em paralelo às reformas que o governo está encaminhando, é imprescindível que se definam os gargalos nas cadeias básicas de suprimentos da economia, especialmente em siderurgia, celulose, química básica, refino de petróleo e petroquímica, com o objetivo de que possam corresponder a taxas de crescimento de, no mínimo, $4 \%$ ao ano, e suportem exportações que resultem em saldos comerciais positivos de, no mínimo, US $\$ 20$ bilhões anuais, necessários para zerar nosso déficit em transações correntes.

No nosso entendimento, o estudo técnico de nossas cadeias produtivas, a revelação de gargalos e a estimativa dos investimentos em cada setor são os primeiros passos a serem dados. As reformas são muito importantes, sem dúvida, mas não farão tudo o que é necessário. Os suprimentos de base constituem o outro lado estratégico da equação de crescimento da economia.

*Artigo publicado no Jornal Gazeta Mercantil, em 23.06.2003
A CST investiu, no ano de 2002, $\mathrm{R} \$ 36,8$ milhões em programas educacionais internos e em projetos sociais e de meio ambiente. Comprometida com ações de responsabilidade social e com o desenvolvimento sustentável, a CST pretende investir cerca de $\mathrm{R} \$ 3,5 \mathrm{mi}-$ lhões no exercício de 2003, somente em projetos comunitários.

No âmbito social, a CST fechou o ano de 2002 com 47 projetos em andamento, beneficiando diretamente $15 \mathrm{mil}$ pessoas. Entre as iniciativas, destaque para "Escola Campeã", um convênio assinado com o Instituto Ayrton Senna, que promove a melhoria do ensino fundamental da Serra (município onde está instalada a CST) e atende a 4,5 mil crianças com enfoque na alfabetização e na aceleração da aprendizagem.

Outro projeto que contou com o apoio da CST foi o Universidade para Todos, curso pré-vestibular gratuito, desenvolvido desde 1996, pela iniciativa de ex-alunos da Universidade Federal do Espírito Santo (Ufes) e com a participação da companhia. Cerca de mil alunos são beneficiados a cada ano, com maiores chances de ingressar na faculdade.

Em 2002, a CST ficou novamente em primeiro lugar entre as empresas brasileiras do setor industrial com maior nível de satisfação dos empregados, conforme levantamento da Hay do Brasil. Atualmente, todos os 3,6 mil empregados da companhia contam, no mínimo, com formação de ensino médio, cerca de um terço possui o nível superior e, destes, $42 \%$ têm pós-graduação, além da companhia manter um programa contínuo de treinamento e aperfeiçoamento profissional. Mais informações poderão ser enocntradas no site da empresa. 


\section{Abastecimento do Mercado e os preços do aço}

Dirigentes do Instituto Brasileiro de Siderurgia - IBS estiveram reunidos com o Ministro do Desenvolvimento, Indústria e Comércio Exterior - MDIC, Luiz Fernando Furlan, em 11.03, em Brasília, para apresentar análise detalhada das condições de abastecimento do aço ao mercado interno e da evolução dos fatores de custo, responsável pelo reajuste dos preços do aço.

Os representantes da siderurgia demonstraram, com números, que foi bem sucedido o esforço do setor de manter a indústria consumidora plenamente abastecida. Desse modo os problemas surgidos no final do ano passado, decorrentes de previsões pessimistas de alguns setores consumidores quanto à demanda daquele período, já foram quase totalmente superados através do aumento da oferta interna, em detrimento das exportações. O IBS ressaltou que o setor siderúrgico dispõe de capacidade instalada de produção de 32 milhões de tone- ladas de aço bruto enquanto a demanda do mercado interno situa-se no entorno de 18 milhões de toneladas.

Os reajustes ocorridos no aço, segundo os dados individuais de cada empresa, resultaram em grande parte dos efeitos da variação cambial na cotação dos insumos importados bem como daqueles referidos a preços internacionais. Além disso, foram, em média, bastante inferiores aos valores indicados pelos setores consumidores em recente carta ao MDIC.

Se a intenção fosse obter maior receita com os preços de exportações, as empresas não redirecionariam sua oferta para melhorar o abastecimento do mercado interno, já que isto significa, nas condições atuais, para alguns produtos, perda de receita de 50 a 100 dólares, em média, por tonelada comercializada.

Lembraram, ainda, os dirigentes do IBS, que a siderurgia mundial - Brasil in- clusive - vinha acumulando prejuízos há vários anos e que o atual nível internacional de preços já apresenta sinais de decréscimo, comprovando o caráter cíclico que caracteriza o mercado mundial de aço.

Por último, os diretores do IBS manifestaram repúdio ao pleito de alguns segmentos consumidores de aço para aplicação de tributação ou contingenciamento das exportações do setor, pois representam quebra de confiança e abandono das regras do mercado, que eles se lembram de defender somente quando lhes convêm. Ressaltaram, a propósito, o aumento médio de 29,5\% nas exportações dos setores intensivos em aço no segundo semestre de 2002, em comparação com o semestre imediatamente anterior, demonstrando, assim, que o aço não constituiu restrição à competitividade dos referidos setores.

Fonte: Notícias do IBS

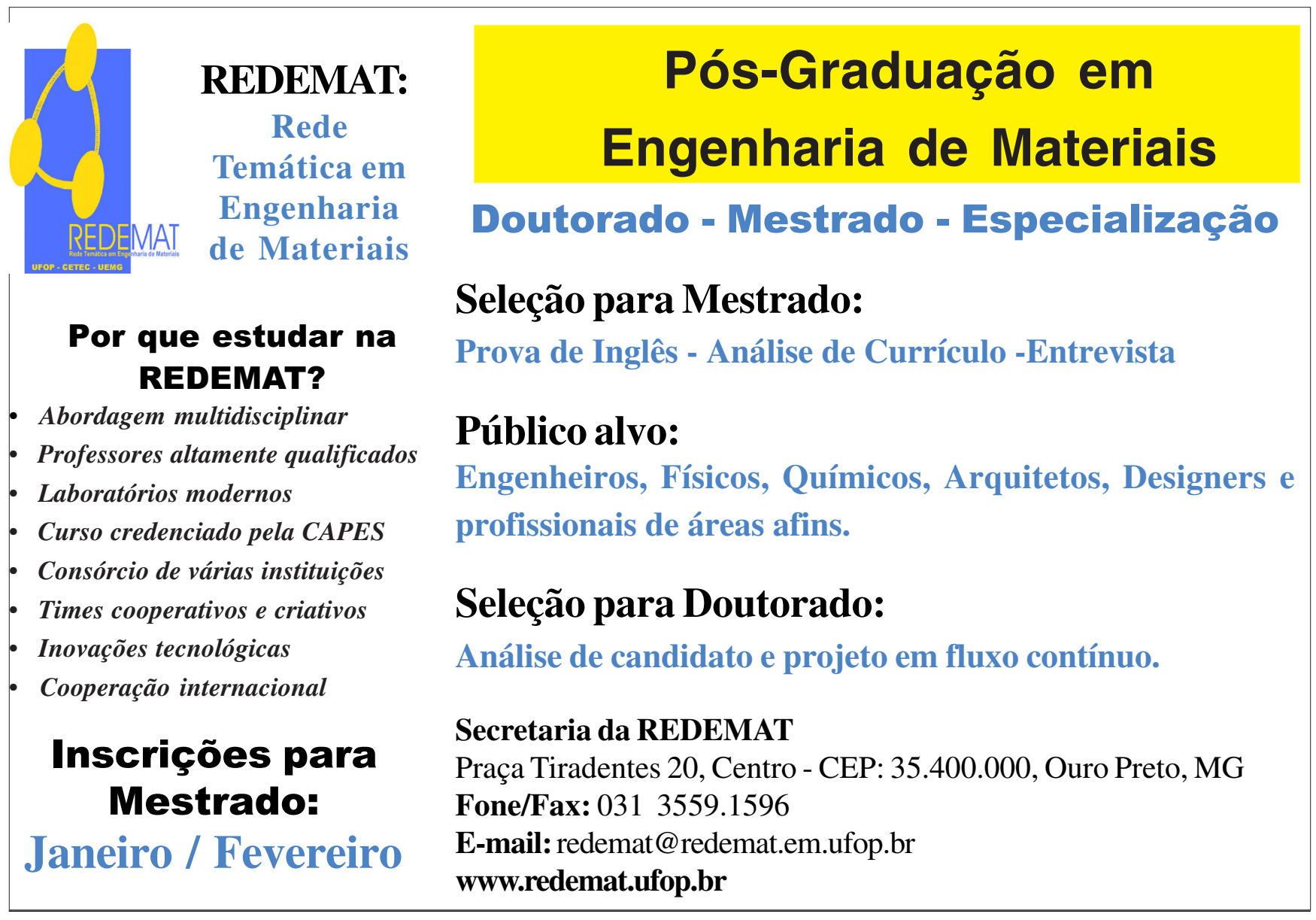




\section{Você tem um encontro marcado em Ouro Preto no dia 04 de outubro de 2003}

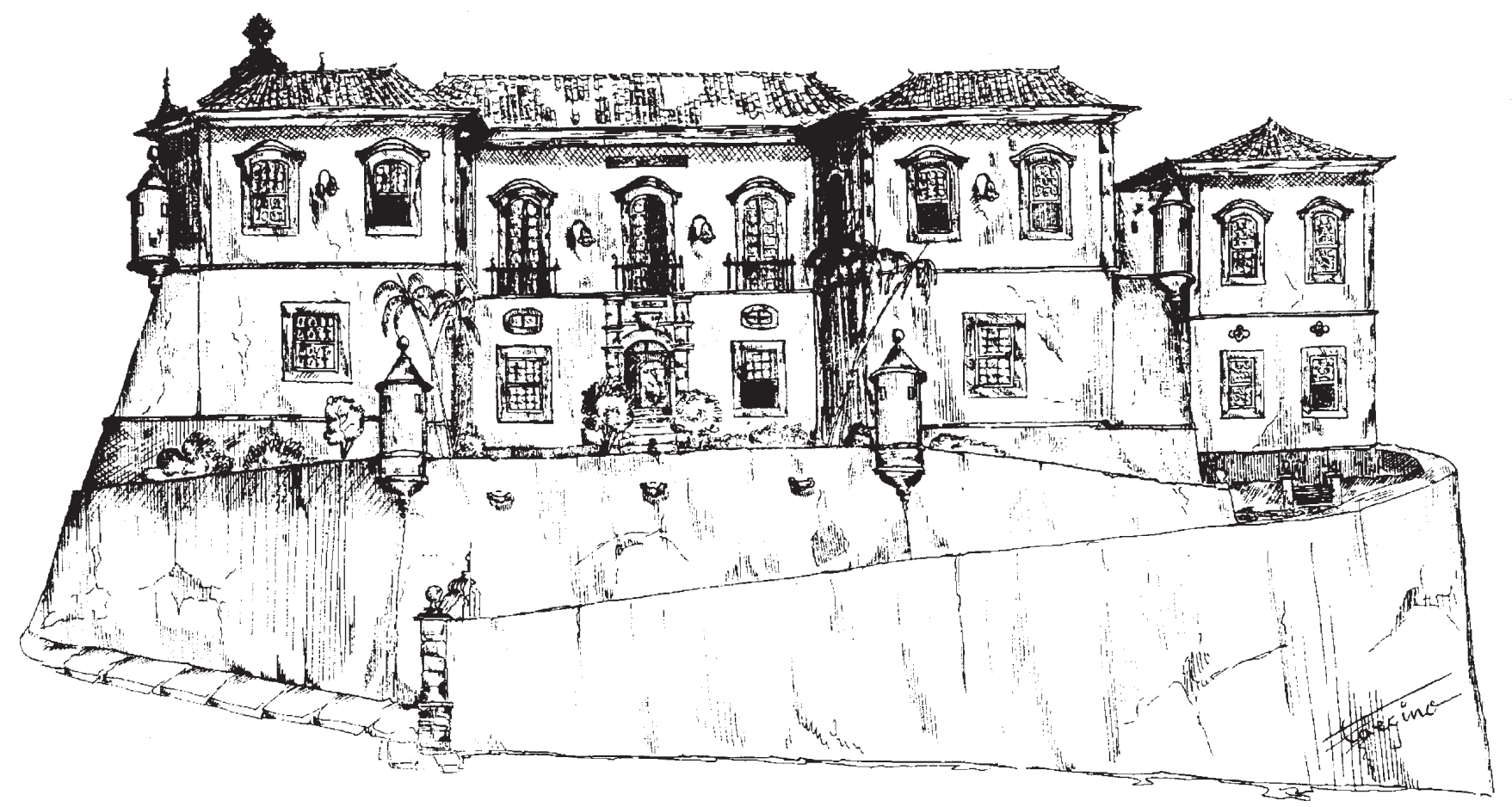

\section{Venha comemorar o 12 de outubro com a gente: Escola de Minas - 127 anos}

